\title{
Human fetal neuroblast and neuroblastoma transcriptome analysis confirms neuroblast origin and highlights neuroblastoma candidate genes
}

Katleen De Preter ${ }^{\not *}$, Jo Vandesompele ${ }^{\not *}$, Pierre Heimann ${ }^{\dagger}$, Nurten Yigit ${ }^{*}$, Siv Beckman ${ }^{\ddagger}$, Alexander Schramm ${ }^{\S}$, Angelika Eggert\$,

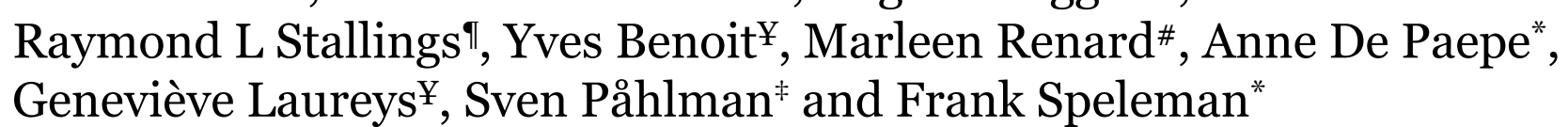

Addresses: *Center for Medical Genetics, Ghent University Hospital, De Pintelaan, B-90oo Ghent, Belgium. ${ }^{\dagger}$ Department of Medical Genetics, University Hospital Erasme, Lenniksebaan, B-1070 Brussels, Belgium. *Division of Molecular Medicine, Department of Laboratory Medicine, Lund University, University Hospital MAS, SE-20502 Malmö, Sweden. §Department of Pediatric Oncology and Hematology, University Hospital of Essen, Hufelandstr, Essen 45122, Germany. "Children's Cancer Research Institute, University of Texas Health Science Center, Floyd Curl Drive, Mail Code 7784, San Antonio, Texas 78229-3900, USA. ${ }^{¥}$ Department of Pediatrics, Ghent University Hospital, De Pintelaan, B9000 Ghent, Belgium. \#Department of Pediatrics, UZ Gasthuisberg, Herestraat, B-30oo Leuven, Belgium.

These authors contributed equally to this work.

Correspondence: Frank Speleman. Email: franki.speleman@ugent.be

Published: 21 September 2006

Genome Biology 2006, 7:R84 (doi:10.1 I86/gb-2006-7-9-r84)

The electronic version of this article is the complete one and can be found online at http://genomebiology.com/2006/7/9/R84
Received: 6 July 2006

Revised: 17 August 2006

Accepted: 21 September 2006

(c) 2006 Preter et al.; licensee BioMed Central Ltd.

This is an open access article distributed under the terms of the Creative Commons Attribution License (http://creativecommons.org/licenses/by/2.0), which permits unrestricted use, distribution, and reproduction in any medium, provided the original work is properly cited.

\begin{abstract}
Background: Neuroblastoma tumor cells are assumed to originate from primitive neuroblasts giving rise to the sympathetic nervous system. Because these precursor cells are not detectable in postnatal life, their transcription profile has remained inaccessible for comparative data mining strategies in neuroblastoma. This study provides the first genome-wide mRNA expression profile of these human fetal sympathetic neuroblasts. To this purpose, small islets of normal neuroblasts were isolated by laser microdissection from human fetal adrenal glands.
\end{abstract}

Results: Expression of catecholamine metabolism genes, and neuronal and neuroendocrine markers in the neuroblasts indicated that the proper cells were microdissected. The similarities in expression profile between normal neuroblasts and malignant neuroblastomas provided strong evidence for the neuroblast origin hypothesis of neuroblastoma. Next, supervised feature selection was used to identify the genes that are differentially expressed in normal neuroblasts versus neuroblastoma tumors. This approach efficiently sifted out genes previously reported in neuroblastoma expression profiling studies; most importantly, it also highlighted a series of genes and pathways previously not mentioned in neuroblastoma biology but that were assumed to be involved in neuroblastoma pathogenesis.

Conclusion: This unique dataset adds power to ongoing and future gene expression studies in neuroblastoma and will facilitate the identification of molecular targets for novel therapies. In addition, this neuroblast transcriptome resource could prove useful for the further study of human sympathoadrenal biogenesis. 


\section{Background}

Neuroblastoma is the most common and deadly extracranial solid childhood tumor, exhibiting remarkable variation in clinical presentation ranging from localized to highly metastatic disease. Despite multimodal therapies, survival rates for aggressive neuroblastomas are still disappointingly low. One possible approach to development of more efficient and less toxic therapies is to gain insight into the signaling pathways that are deregulated in neuroblastoma and to use this information in the design of molecular therapies. However, at present only two genes, namely $M Y C N$ and $\mathrm{PHOX}_{2} \mathrm{~B}$, have been directly linked to neuroblastoma development, although their exact role in oncogenesis is still unclear $[1,2]$.

It is hoped that genome-wide gene expression studies will provide insights into the genes and molecular pathways that govern neuroblastoma pathogenesis. Thus far, no clear or consistent candidate genes or pathways have emerged from these analyses [3-5] (see Additional data file 3 for more references). Both for currently available expression data and forthcoming datasets, we anticipate that transcriptome information on the cells of origin of neuroblastoma (sympathetic nervous system progenitors) will be of crucial importance and could provide significant power on data mining strategies.

The sympathetic nervous system is composed of sympathetic chain and truncus ganglia, paraganglia, and the adrenal gland. Ganglion cells (neuroblasts during development) are the major cell type of chain and truncus ganglia, and extraadrenal chromaffin cells form the paraganglia, whereas the adrenal gland is composed of adrenal chromaffin cells and, at least during development, sympathetic neuroblasts. The fate of the neuroblasts in the developing human adrenal gland is not clear; some or all may involute or mature as solitary intraadrenal neurons [6]. Evidence for the cellular origin of neuroblastoma is based on their occurrence in the adrenal gland or along the spinal cord in association with sympathetic ganglia, and on their neuroblastic phenotype that indicates that the tumor cells are derived from immature sympathetic nervous system cells of the ganglionic lineage [7]. Indeed, cells of adrenal neuroblastomas have neuroblastic morphology and do not express the adrenal chromaffin marker PNMT, but they share phenotypic characteristics with the immature sympathetic neuroblasts present as nests of cells in the developing adrenal gland. However, a small subset of neuroblastomas also contains cells with extra-adrenal chromaffin characteristics.

In the present study we isolated and performed expression profiling of the human adrenal neuroblasts as they form monocellular structures during early fetal stages, which can be easily microdissected. In parallel, favorable and unfavorable neuroblastoma tumors were profiled on the same platform. Finally, our dataset was integrated in a meta-analytical data mining approach.

\section{Results \\ Characterization, isolation, and gene expression profiling of fetal adrenal neuroblasts}

Prescreening of hematoxylin-eosin cryosections from 11 fetal adrenal glands demonstrated that large neuroblast clusters of more than 100 cells were predominantly found in adrenal glands at 19 and 20 weeks' gestational age (Figure 1a). To verify that these cell clusters indeed represent neuroblasts and to estimate the degree of intermingled chromaffin cells, cryosections were stained for the neuronal and chromaffin marker TH (tyrosine hydroxylase), the chromaffin marker CHGA (chromogranin A; which also has low expression in neuroblasts), and the neuronal markers BCL2 (B-cell CLL/lymphoma 2) and HNK1 (carbohydrate epitope) [8]. As shown in Figure 1, the clusters of neuroblastic cells stained positive for all markers and, in particular, these cells were positive for BCL2 and HNK1. The majority of chromaffin cells, identified by their strong CHGA and TH expression, were found to be scattered throughout the adrenal cortex (these cells coalesce and form large islands of chromaffin cells later during development), whereas a few cells were located in or adjacent to the neuroblast clusters.

Neuroblast clusters and adjacent cortical cells (used as controls) were isolated using laser capture microdissection from stained cryosections from three different fetal adrenal glands (glands 1, 2 and 3, which were of gestational ages 20, 19 and 19 weeks, respectively) (Figure 2) and immediately lysed in RNA extraction buffer. In order to obtain a sufficient amount of good quality neuroblast RNA for oligonucleotide chip analyses, we applied a previously validated protocol for tissue sectioning, staining, and microdissection [9] (Additional data file 1(a)). By pooling different isolates of the same adrenal gland, between 2.5 and $15 \mathrm{ng}$ total RNA could be obtained for each of the three neuroblast samples (Additional data file 1(b)). After two-round amplification and labeling of three neuroblast, three cortex, and 18 neuroblastoma RNA samples, hybridization was performed on HG-U133A Affymetrix oligonucleotide chips. Real-time polymerase chain reaction analysis of selected genes showed that there was no RNA amplification bias in the chip data (Additional data file 1(c)).

\section{Validation of the expression profile of fetal adrenal neuroblasts and cortex cells}

The expression profiles of the neuroblast and cortex samples were compared using the rank product nonparametric method, which is particularly suited for extracting significantly differentially expressed genes in a limited number of samples [10]. Two lists of 156 and 86 unique genes were established with significantly higher expression in neuroblast and adrenal cortex cells, respectively (multiple testing corrected $P<0.01$; Additional data file 2). Gene Ontology (GO) analysis identified those classes of genes that are significantly over-represented in the cell specific gene lists $(P<0.01$; Table 1). As expected, the neuroblast gene list is enriched for genes that are involved in catecholamine metabolism, neurogenesis 

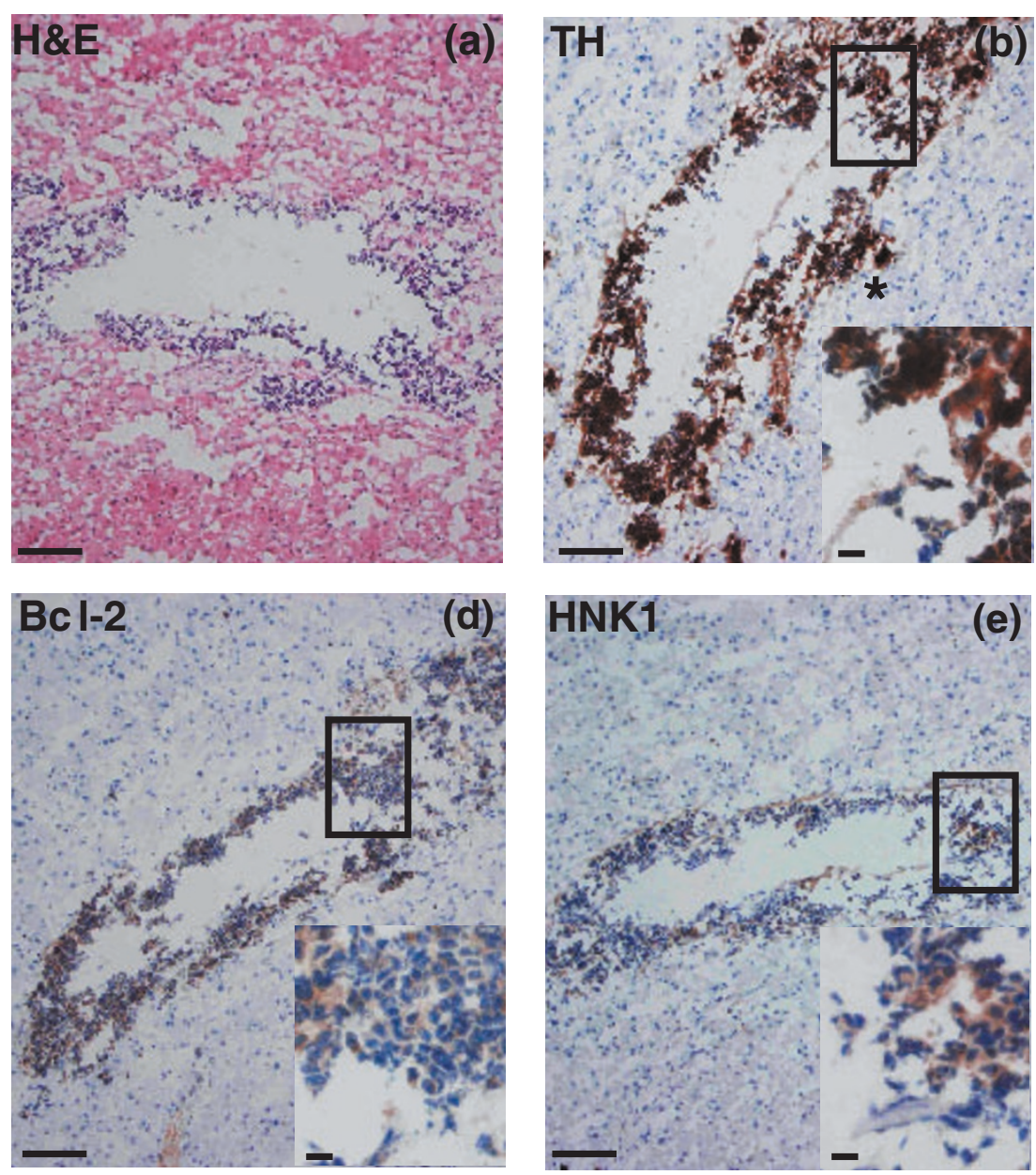
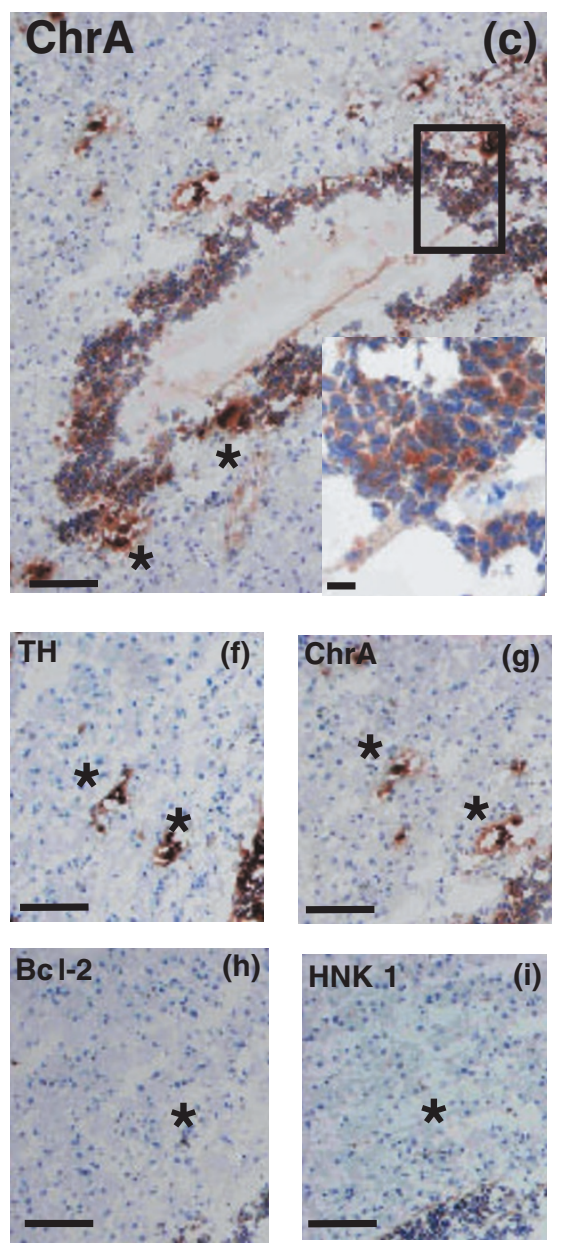

\section{Figure I}

Identification of sympathetic neuroblasts and chromaffin cells in human fetal adrenal glands by immunohistochemical analysis. Sections of a human fetal ( 19 weeks) adrenal gland, adjacent to those used for laser capture retrieval of cells for mRNA extraction and gene expression profiling, were stained with (a)

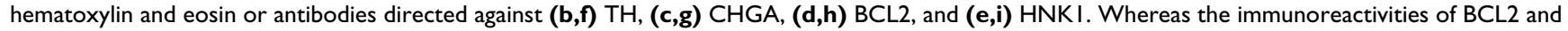
HNKI are specific for neuroblasts, TH and CHGA expression is pronounced in chromaffin cells and weak in neuroblasts [8]. Stars indicate chromaffin cells $\left(\mathrm{TH}^{+}, \mathrm{CHGA}^{+}, \mathrm{BCL2}^{-}\right.$, and $\left.\mathrm{HNKI}^{-}\right)$, either solitary or intermingled with neuroblasts. Panels a-e show a cluster of adrenal neuroblasts and panels $\mathrm{f}-\mathrm{i}$ show cortical area within scattered chromaffin cells adjacent to the neuroblast cluster. Inserts in panels b-e (bars: $10 \mu \mathrm{m})$ correspond to the boxed areas in these panels (bars in panels a-i: $100 \mu \mathrm{m}$ ). BCL2, B-cell CLL/lymphoma 2; CHGA, chromogranin A; H\&E, hematoxylin and eosin; HNKI, carbohydrate epitope; TH, tyrosine hydroxylase.

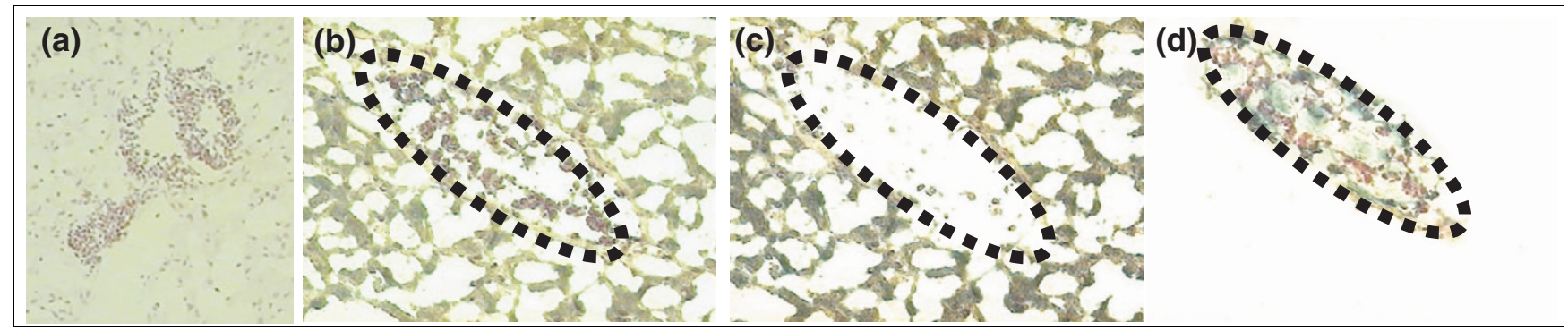

\section{Figure 2}

Laser capture microdissection of neuroblast clusters. (a) Large cluster of neuroblasts in fetal adrenal glands at 19 weeks' gestational age (mounted hematoxylin and eosin stained cryosections), (b,c) unmounted hematoxylin and eosin stained fetal adrenal cryosections with a neuroblast cluster before and after microdissection (sample 2), and (d) the microdissected neuroblast cluster. 
Table I

GO analysis: neuroblast versus cortex samples

\begin{tabular}{|c|c|c|c|}
\hline GO & $P$ value & $n$ & GO description \\
\hline \multicolumn{4}{|c|}{ More highly expressed in neuroblast compared to cortex } \\
\hline GO:0007399 & $5.94 \mathrm{E}-09$ & 20 & Neurogenesis \\
\hline GO:0019226 & I. $12 \mathrm{E}-06$ & 13 & Transmission of nerve impulse \\
\hline GO:0007268 & $5.39 \mathrm{E}-06$ & 12 & Synaptic transmission \\
\hline GO:000I505 & $9.29 \mathrm{E}-05$ & 5 & Regulation of neurotransmitter levels \\
\hline GO:0007267 & $2.76 \mathrm{E}-04$ & 16 & Cell-cell signaling \\
\hline GO:0050877 & 3.17E-04 & 16 & Neurophysiological process \\
\hline GO:0046879 & 3.47E-04 & 3 & Hormone secretion \\
\hline GO:0006584 & 3.47E-04 & 3 & Catecholamine metabolism \\
\hline GO:0018958 & $4.72 \mathrm{E}-04$ & 3 & Phenol metabolism \\
\hline GO:00485I3 & $6.67 \mathrm{E}-04$ & 22 & Organ development \\
\hline GO:0006836 & $6.96 \mathrm{E}-04$ & 4 & Neurotransmitter transport \\
\hline GO:0009887 & $7.32 \mathrm{E}-04$ & 21 & Organogenesis \\
\hline GO:0007I54 & $\mathrm{I} .2 \mathrm{IE}-03$ & 46 & Cell communication \\
\hline GO:0045055 & $1.25 \mathrm{E}-03$ & 3 & Regulated secretory pathway \\
\hline GO:0007269 & $1.25 \mathrm{E}-03$ & 3 & Neurotransmitter secretion \\
\hline GO:0046903 & I.52E-03 & 8 & Secretion \\
\hline GO:0030072 & $2.09 \mathrm{E}-03$ & 2 & Peptide hormone secretion \\
\hline GO:0030073 & $2.09 \mathrm{E}-03$ & 2 & Insulin secretion \\
\hline GO:0016079 & $2.09 \mathrm{E}-03$ & 2 & Synaptic vesicle exocytosis \\
\hline GO:0042423 & $2.09 \mathrm{E}-03$ & 2 & Catecholamine biosynthesis \\
\hline GO:0006887 & $2.24 \mathrm{E}-03$ & 4 & Exocytosis \\
\hline GO:0009653 & $2.77 \mathrm{E}-03$ & 23 & Morphogenesis \\
\hline GO:00072I8 & $3.25 \mathrm{E}-03$ & 4 & Neuropeptide signaling pathway \\
\hline GO:0007275 & $3.26 \mathrm{E}-03$ & 29 & Development \\
\hline GO:0046883 & $5.70 \mathrm{E}-03$ & 2 & Regulation of hormone secretion \\
\hline GO:0030I82 & $7.26 \mathrm{E}-03$ & 2 & Neuron differentiation \\
\hline GO:0048489 & $8.98 \mathrm{E}-03$ & 2 & Synaptic vesicle transport \\
\hline \multicolumn{4}{|c|}{ More highly expressed in cortex compared to neuroblast } \\
\hline GO:0016126 & 4. $18 \mathrm{E}-07$ & 5 & Sterol biosynthesis \\
\hline GO:0006694 & $9.28 \mathrm{E}-07$ & 6 & Steroid biosynthesis \\
\hline GO:0008202 & $4.32 \mathrm{E}-06$ & 7 & Steroid metabolism \\
\hline GO:0016125 & $2.93 \mathrm{E}-05$ & 5 & Sterol metabolism \\
\hline GO:0044255 & $6.74 \mathrm{E}-05$ & 9 & Cellular lipid metabolism \\
\hline GO:0006629 & $8.75 \mathrm{E}-05$ & 10 & Lipid metabolism \\
\hline GO:0008610 & I.39E-04 & 6 & Lipid biosynthesis \\
\hline GO:0006695 & 2.97E-04 & 3 & Cholesterol biosynthesis \\
\hline GO:0006066 & I.17E-03 & 6 & Alcohol metabolism \\
\hline GO:0008203 & 4.69E-03 & 3 & Cholesterol metabolism \\
\hline GO:0044242 & 4.97E-03 & 2 & Cellular lipid catabolism \\
\hline GO:0006II8 & $7.90 \mathrm{E}-03$ & 5 & Electron transport \\
\hline
\end{tabular}

Shown are over-represented GO classes (biological process) (with $P<0.01$ and at least two genes) in the list of genes that are more highly expressed in neuroblast than in cortex samples, and vice versa. GO, Gene Ontology.

and other neural processes, whereas cortex cells specifically express genes involved in steroid and cholesterol metabolism.
To further test the validity of the neuroblast gene expression profile, we evaluated the expression of known neuronal and chromaffin markers that were previously studied in human fetal sections [8]. High expression (among the 10\% most 
abundant genes) of neuronal markers (BCL2, GAP43, and $N P Y$ ) together with chromaffin (and to a lesser extent neuronal) markers (CHGA, CHGB, DBH, DDC and $T H$ ) and an adrenal chromaffin marker (PNMT) in the microdissected cell clusters is in keeping with our observation that the neuroblast isolates are pure, with only rare intermingled chromaffin cells (Figure 1).

Gene set enrichment analysis [11] based on expression of the 156 neuroblast-specific genes in 79 human tissues [12] was performed in order to explore whether the microdissected neuroblasts indeed have neural characteristics. The neuroblasts exhibit a significant overlap in expression with various nervous system tissues $(P<0.05$; fetal brain, prefrontal cortex, brain amygdale, whole brain, occipital lobe, and hypothalamus), further demonstrating that the proper cells were microdissected.

\section{Similarity between the expression profiles of neuroblast and neuroblastoma further supports the 'cell of origin' concept}

Although multiple lines of evidence indicate that neuroblastoma originates from immature sympathetic neuroblasts, the mRNA expression repertoire of these neuroblasts and neuroblastomas have not yet been compared. Before our analysis, we assumed that, in addition to differences resulting from oncogenic transformation, both cell populations would exhibit many cell type specific similarities.

Three data mining strategies were employed to investigate this hypothesis. First, an unbiased multidimensional scaling of all genes on the chip showed that the neuroblasts cluster close to the neuroblastoma tumors and that both groups cluster far away from the fetal adrenal cortex cells (Figure 3a). Second, we extended our dataset with publicly available expression profiles (measured on the same platform) from 79 normal tissues [12] and three neural stem cell cultures [13]. Based on the genes that are differentially expressed between the neuroblasts and cortex samples (156 and 86 genes, respectively), multidimensional scaling showed again that the neuroblastoma tumors cluster close to the neuroblasts and further away from the other normal tissues. Interestingly, the neural stem cells also cluster close to the neuroblastomas and neuroblasts (Figure $3 \mathrm{~b}$ ). These findings further support the notion that adrenal neuroblasts are indeed of neuronal origin with possible neuronal stem cell features, and the observed considerable similarities to neuroblastomas in terms of expression give further strength to the 'cell of origin' hypothesis for neuroblastoma development.

Third, we looked for similarities in mRNA expression between neuroblast and neuroblastoma by cataloging their expression repertoire. We defined a reasonable cut-off to determine whether a gene is expressed or not in a given sample (the mean percentage of present calls for the various chips; Additional data file 1(d)). As such, the $36 \%$ most highly expressed probe IDs in the cortex, neuroblast and neuroblastoma cells, were selected and compared in a Venn diagram. This analysis clearly shows that neuroblasts have more expressed genes in common with neuroblastoma than with the cortex cells (432 versus 292; Figure 4a). GO analysis on the common 432 genes revealed an expected over-representation of neurogenesis genes $(P<0.01$; data not shown $)$. Next, we zoomed in on neurogenesis and transcription factor ontology classes by performing a similar Venn diagram for these gene sets, assuming their putative importance in neuroblastoma development. Interestingly, the similarities between neuroblast and neuroblastoma are even more pronounced for these two GO classes (Figure 4b, c).

\section{Identifying genes and pathways putatively implicated in neuroblastoma pathogenesis through differential expression analysis of normal neuroblasts and neuroblastomas}

In the final and most challenging part of our data mining approach, we aimed to identify genes that are underexpressed or over-expressed in neuroblastomas compared with neuroblasts, because these genes and the pathways that they govern might be involved in neuroblastoma development or represent markers for the stage of developmental arrest of neuroblastomas. Rank product analysis (multiple testing corrected $P<0.01$ ) yielded a list of 71 genes that were more highly expressed in neuroblasts and 565 genes that were more highly expressed in neuroblastomas (Additional data file 2).

A first crucial step in our data mining strategy to identify genes that are putatively involved in neuroblastoma was a meta-analysis of our generated gene lists in published neuroblastoma microarray data. We used the Neuroblastoma Gene Server (NBGS) which was developed in-house (see Additional data file 3 for detailed information) to compare the neuroblast-specific and neuroblastoma-specific gene lists with genes that have been reported as differentially expressed in 25 previous gene expression profiling studies conducted in neuroblastoma (Additional data file 3). We found that as many as 17 of the 71 genes (24\%) that are over-expressed in neuroblasts relative to neuroblastomas were reported in the NBGS, mainly annotated as genes that are more highly expressed in maturing, differentiating, or localized neuroblastomas. Likewise, 102 out of the 565 genes (18\%) that were over-expressed in neuroblastoma were previously identified in other gene expression studies on neuroblastoma. The high overlap of our gene lists with published gene lists demonstrates the validity of our lists, which were subsequently further explored in chromosomal mapping, GO, and pathway analysis.

\section{Positional expression mapping of candidate oncogenes and tumor suppressor genes}

Chromosome 17q gain is the most frequent genetic aberration in neuroblastoma and is assumed to play a crucial role in its 


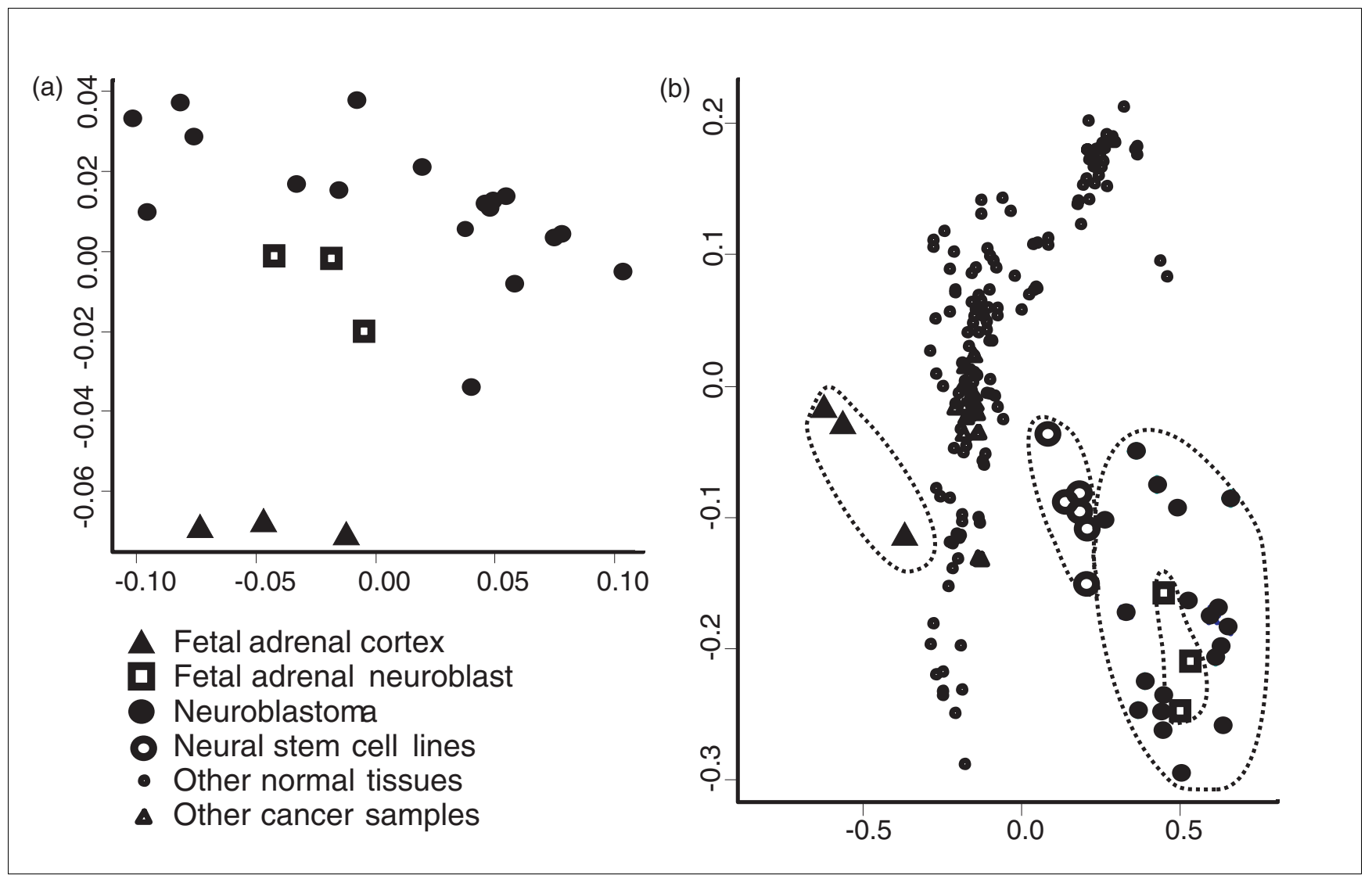

Figure 3

Multidimensional scaling of neuroblast, cortex, and neuroblastoma samples. (a) Multidimensional scaling of neuroblast, cortex, and neuroblastoma samples using all genes (Spearman correlation) and (b) multidimensional scaling of neuroblast, cortex, neuroblastoma, 79 normal tissue samples and other cancer samples (in duplo), and three neural stem cell cultures using the genes that are differentially expressed between fetal adrenal neuroblast and fetal adrenal cortex shows that the neuroblasts cluster very close to the neuroblastomas.
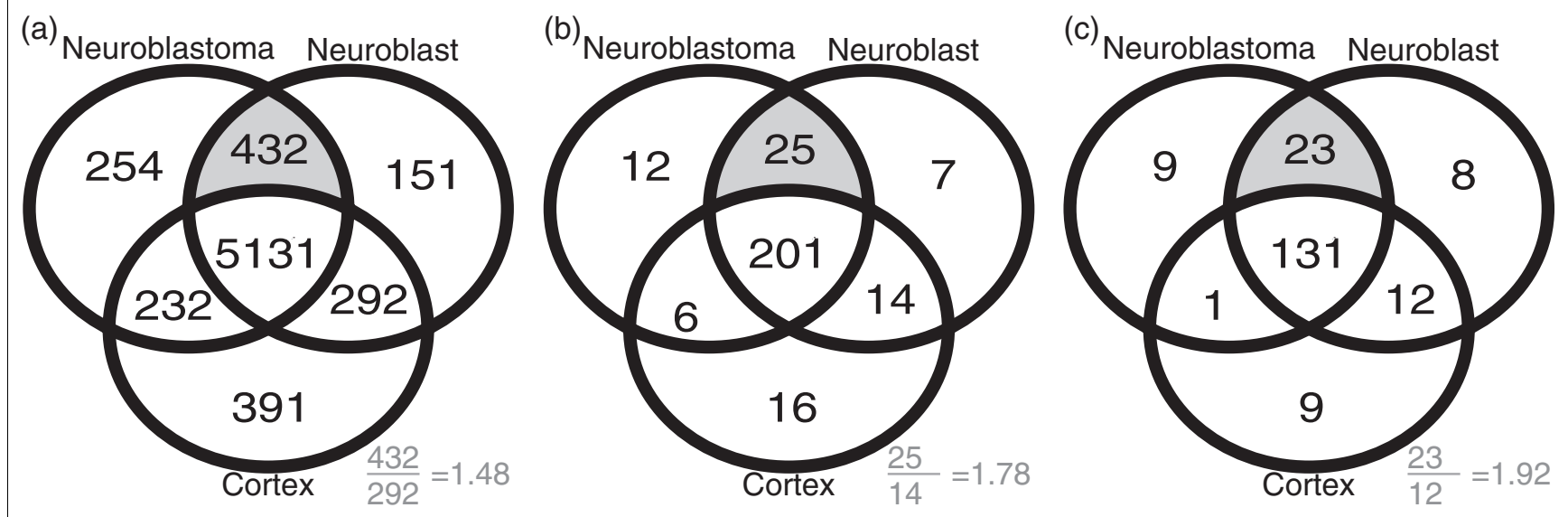

Figure 4

Venn diagram analysis of the genes with detectable expression in neuroblastoma, neuroblast, and cortex samples. (a) All genes, (b) transcription factors (GO:0003700), and (c) neurogenesis genes (GO:0007399). The number of genes that are in common between neuroblast and neuroblastoma is higher than the number of genes that are in common between the neuroblasts and cortex samples (especially for the gene classes transcription and neurogenesis), indicating that neuroblastomas resemble neuroblasts. GO, Gene Ontology. 


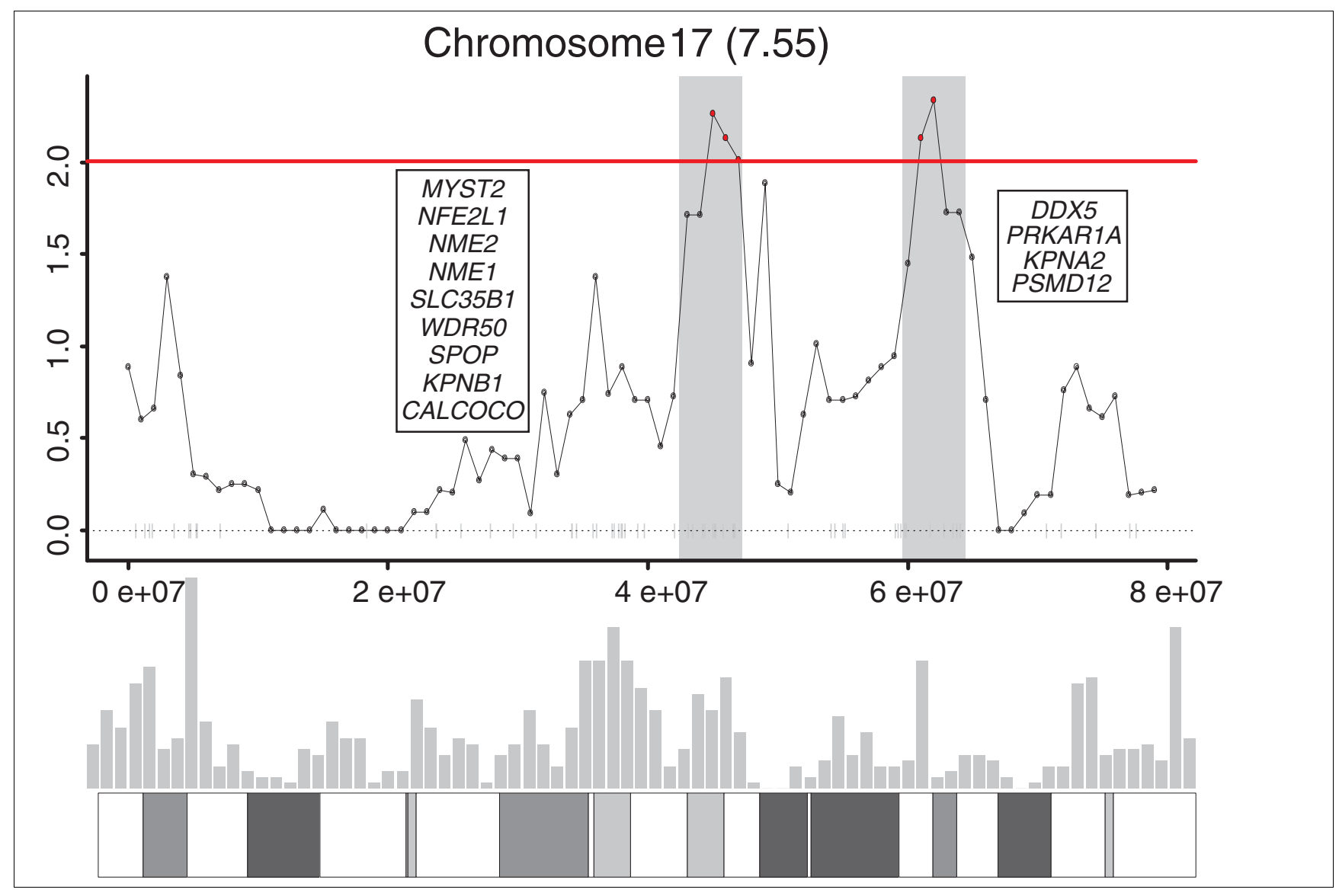

Figure 5

Positional gene enrichment analysis of genes on chromosome 17. Positional gene enrichment analysis for the genes that are more highly expressed in neuroblastoma compared to normal neuroblasts identified two regions on $17 q$ with significant over-representation (- 10 log $P$ values; indicated in grey; the genes in these regions are printed in the boxes). The horizontal red line indicates the multiple testing corrected $P$ value of 0.01 , above which the positional gene enrichment value denotes significant over-representation. Vertical lines show the position of the genes on chromosome I 7 from the gene list under investigation. The boxplot shows the gene density along the chromosome.

pathogenesis through a dosage effect of one or more genes. This critical region still comprises 25 megabases (Mb) [14], precluding straightforward candidate gene identification. Here we apply an alternative, intuitive strategy to pinpoint putative critical dosage sensitive loci. Using positional gene enrichment analysis (De Preter and coworkers, unpublished data) [15], we sought chromosomal loci that are significantly over-represented in the list of genes that are over-expressed in neuroblastoma relative to their normal cells of origin (Figure 5). We found two peaks on chromosome 17q, with high significance for a locus on 17q21.32-q22 that coincides with the consistently gained segment just distal from the most distal breakpoint in a series of high-resolution copy number profiles (Vandesompele and coworkers, unpublished data).

Apart from over-expressed genes, we also sought positional tumor suppressor genes by mapping under-expressed genes (relative to normal neuroblasts). The following positional candidates could be identified, located within or very close to the known shortest regions of overlap in neuroblastoma:
CASP9 on 1p36; CACNA2D3, TDGF1 and NKTR on 3p21-p22 (SRO (shortest region of overlap) from [16]); IGSF4, APOA1, $M L L$ and $R D X$ on 11q23 [17-19]; and MEG3 and DLK1 on $14 \mathrm{q} 32$ [20].

\section{GO analysis}

To examine gene expression differences between neuroblasts and neuroblastomas from a different perspective, we mapped the neuroblast-specific and neuroblastoma-specific gene lists to the biologic process GO classification (Table 2). This revealed that the neuroblasts express significantly $(P<0.01)$ more genes that are involved in steroid and catecholamine metabolism compared with neuroblastomas. Neuroblastomas are characterized by an over-representation of genes that are involved in immune response, cell growth, and cell cycle. The immune response gene signature may be due to infiltrating immune cells, whereas the over-representation of cell growth and cell cycle genes in neuroblastomas is in perfect concordance with the hyperproliferative character of tumors. 
Table 2

GO analysis: normal neuroblasts compared to neuroblastomas

\begin{tabular}{|c|c|c|c|}
\hline GO & $P$ value & $n$ & GO description \\
\hline \multicolumn{4}{|c|}{ More highly expressed in neuroblast compared to neuroblastoma } \\
\hline GO:0008202 & $1.33 \mathrm{E}-18$ & 17 & Steroid metabolism \\
\hline GO:0006694 & $3.22 \mathrm{E}-15$ & 12 & Steroid biosynthesis \\
\hline GO:0044255 & $2.13 \mathrm{E}-12$ & 18 & Cellular lipid metabolism \\
\hline GO:0008610 & $8.54 \mathrm{E}-12$ & 13 & Lipid biosynthesis \\
\hline GO:0016125 & $1.29 \mathrm{E}-11$ & 10 & Sterol metabolism \\
\hline GO:0006629 & $1.50 \mathrm{E}-10$ & 18 & Lipid metabolism \\
\hline GO:0008203 & $5.85 \mathrm{E}-09$ & 8 & Cholesterol metabolism \\
\hline GO:0008207 & I.37E-08 & 5 & C2I-steroid hormone metabolism \\
\hline GO:0006700 & I.37E-08 & 5 & $\mathrm{C} 2 \mathrm{I}$-steroid hormone biosynthesis \\
\hline GO:0006066 & $1.55 \mathrm{E}-08$ & 12 & Alcohol metabolism \\
\hline GO:0042446 & $9.26 \mathrm{E}-07$ & 5 & Hormone biosynthesis \\
\hline GO:0016126 & $1.16 \mathrm{E}-06$ & 5 & Sterol biosynthesis \\
\hline GO:0042445 & $9.57 \mathrm{E}-06$ & 5 & Hormone metabolism \\
\hline GO:0006118 & $1.76 \mathrm{E}-05$ & 9 & Electron transport \\
\hline GO:0006869 & $1.84 \mathrm{E}-05$ & 5 & Lipid transport \\
\hline GO:0009058 & $4.62 \mathrm{E}-05$ & 16 & Biosynthesis \\
\hline GO:0006695 & $5.39 \mathrm{E}-04$ & 3 & Cholesterol biosynthesis \\
\hline GO:0042423 & $6.50 \mathrm{E}-04$ & 2 & Catecholamine biosynthesis \\
\hline GO:0006810 & $2.29 \mathrm{E}-03$ & 20 & Transport \\
\hline GO:0006091 & $2.32 \mathrm{E}-03$ & 9 & Generation of precursor metabolites and energy \\
\hline GO:0006584 & $2.85 \mathrm{E}-03$ & 2 & Catecholamine metabolism \\
\hline GO:005I234 & $2.88 \mathrm{E}-03$ & 20 & Establishment of localization \\
\hline GO:0051179 & $3.04 \mathrm{E}-03$ & 20 & Localization \\
\hline GO:0018958 & $3.46 \mathrm{E}-03$ & 2 & Phenol metabolism \\
\hline GO:004240I & $5.64 \mathrm{E}-03$ & 2 & Biogenic amine biosynthesis \\
\hline GO:0042398 & $8.30 \mathrm{E}-03$ & 2 & Amino acid derivative biosynthesis \\
\hline
\end{tabular}

More highly expressed in neuroblastoma compared to neuroblast

\begin{tabular}{|c|c|c|c|}
\hline GO:0019882 & $4.54 \mathrm{E}-14$ & 16 & Antigen presentation \\
\hline GO:0030333 & $2.51 \mathrm{E}-12$ & 14 & Antigen processing \\
\hline GO:0019884 & $1.21 \mathrm{E}-08$ & 8 & Antigen presentation, exogenous antigen \\
\hline GO:0019886 & $3.45 \mathrm{E}-08$ & 8 & Antigen processing, exogenous antigen via MHC class II \\
\hline GO:0019883 & $4.23 \mathrm{E}-07$ & 7 & Antigen presentation, endogenous antigen \\
\hline GO:0006260 & $2.07 \mathrm{E}-06$ & 20 & DNA replication \\
\hline GO:0006955 & $2.45 \mathrm{E}-06$ & 58 & Immune response \\
\hline GO:0006952 & I.02E-05 & 60 & Defense response \\
\hline GO:0019885 & I.03E-05 & 6 & Antigen processing, endogenous antigen via $\mathrm{MHC}$ class I \\
\hline GO:0009607 & $1.05 \mathrm{E}-05$ & 66 & Response to biotic stimulus \\
\hline GO:0006270 & $9.25 \mathrm{E}-05$ & 6 & DNA replication initiation \\
\hline GO:0006259 & 4.34E-04 & 35 & DNA metabolism \\
\hline GO:0009596 & $5.5 \mathrm{IE}-04$ & 4 & Detection of pest, pathogen or parasite \\
\hline GO:000626I & $7.72 \mathrm{E}-04$ & 10 & DNA-dependent DNA replication \\
\hline GO:0050896 & $1.03 \mathrm{E}-03$ & 92 & Response to stimulus \\
\hline GO:0006913 & I.42E-03 & 12 & Nucleocytoplasmic transport \\
\hline GO:000705I & $1.84 \mathrm{E}-03$ & 5 & Spindle organization and biogenesis \\
\hline GO:0016070 & $2.01 \mathrm{E}-03$ & 25 & RNA metabolism \\
\hline GO:0007052 & $2.27 \mathrm{E}-03$ & 4 & Mitotic spindle organization and biogenesis \\
\hline GO:0009595 & $2.27 \mathrm{E}-03$ & 4 & Detection of biotic stimulus \\
\hline GO:0007017 & 2.67E-03 & 11 & Microtubule-based process \\
\hline GO:0006658 & $3.08 \mathrm{E}-03$ & 2 & Phosphatidylserine metabolism \\
\hline GO:0009613 & 3.39E-03 & 34 & Response to pest, pathogen or parasite \\
\hline
\end{tabular}


Table 2 (Continued)

\begin{tabular}{llll}
\hline GO analysis: normal neuroblasts compared to neuroblastomas & \\
\hline GO:0006928 & $3.94 \mathrm{E}-03$ & 18 & Cell motility \\
GO:00400II & $3.94 \mathrm{E}-03$ & 18 & Locomotion \\
GO:0043207 & $4.72 \mathrm{E}-03$ & 34 & Response to external biotic stimulus \\
GO:0007626 & $5.10 \mathrm{E}-03$ & 18 & Locomotory behavior \\
GO:0016043 & $5.31 \mathrm{E}-03$ & 46 & Cell organization and biogenesis \\
GO:0016049 & $6.09 \mathrm{E}-03$ & 12 & Cell growth \\
GO:0008361 & $6.09 \mathrm{E}-03$ & 12 & Regulation of cell size \\
GO:0042254 & $6.39 \mathrm{E}-03$ & 6 & Ribosome biogenesis and assembly \\
GO:0051I69 & $8.15 \mathrm{E}-03$ & 10 & Nuclear transport \\
GO:001607I & $8.34 \mathrm{E}-03$ & 16 & Mrna metabolism \\
GO:004324I & $8.91 \mathrm{E}-03$ & 2 & Protein complex disassembly \\
GO:0031498 & $8.91 \mathrm{E}-03$ & 2 & Chromatin disassembly \\
GO:0006337 & $8.91 \mathrm{E}-03$ & 2 & Nucleosome disassembly \\
GO:0006104 & $8.91 \mathrm{E}-03$ & 2 & Succinyl-coa metabolism \\
GO:0007610 & $9.44 \mathrm{E}-03$ & 21 & Behavior \\
GO:0007049 & $9.50 \mathrm{E}-03$ & 39 & Cell cycle \\
\hline
\end{tabular}

Shown are over-represented GO classes (biological process) (with $P<0.01$ and at least two genes) in the list of genes that are more highly expressed in normal neuroblasts than in neuroblastomas, and vice versa. GO, Gene Ontology.

We then specifically looked at genes belonging to GO terms neurogenesis, transcription factor activity, and apoptosis; these three processes can be assumed to play an important role in neuroblastoma pathogenesis (Table 3 ). This analysis identified the following interesting genes from the neuroblast-specific and neuroblastoma-specific gene lists: transcription factors involved in neurogenesis TFAP2B (6p12.3; more highly expressed in neuroblasts); ASCL1 (12q23.2), SIX3 (2p21) and STAT3 (17q21.2; more highly expressed in neuroblastoma); and APOE (19q13.31) and INHBA (7p14.1; more highly expressed in neuroblastoma), which are involved in both apoptosis and neurogenesis.

\section{Differential expression analysis of favorable and unfavorable neuroblastomas}

Thus far, most published microarray studies on neuroblastomas mainly compared favorable with unfavorable neuroblastomas in order to identify prognostic markers or pathways that are involved in these clearly different neuroblastoma tumor types. In order to add value to such an analysis, we contrasted similar differentially expressed gene lists with the normal neuroblast expression profile (Additional data file 2). In a first step, we compared the differentially expressed genes between these two tumor types with published prognostic gene lists. We found that 25 of the 194 genes on our list were previously reported, including the well established markers MYCN, NTRK1, and CD44 (see NBGS analysis in Additional data file 3 ). This overlap demonstrates the validity of the selected neuroblastoma panel and their expression profile. Subsequently, we sought the corresponding gene expression levels of the differentially expressed genes in the normal counterpart cells, aiming to select neuroblastoma candidate genes. Of the 95 genes that are more highly expressed in favorable tumors (versus unfavorable ones), 37 also have significant differential expression (either higher or lower)

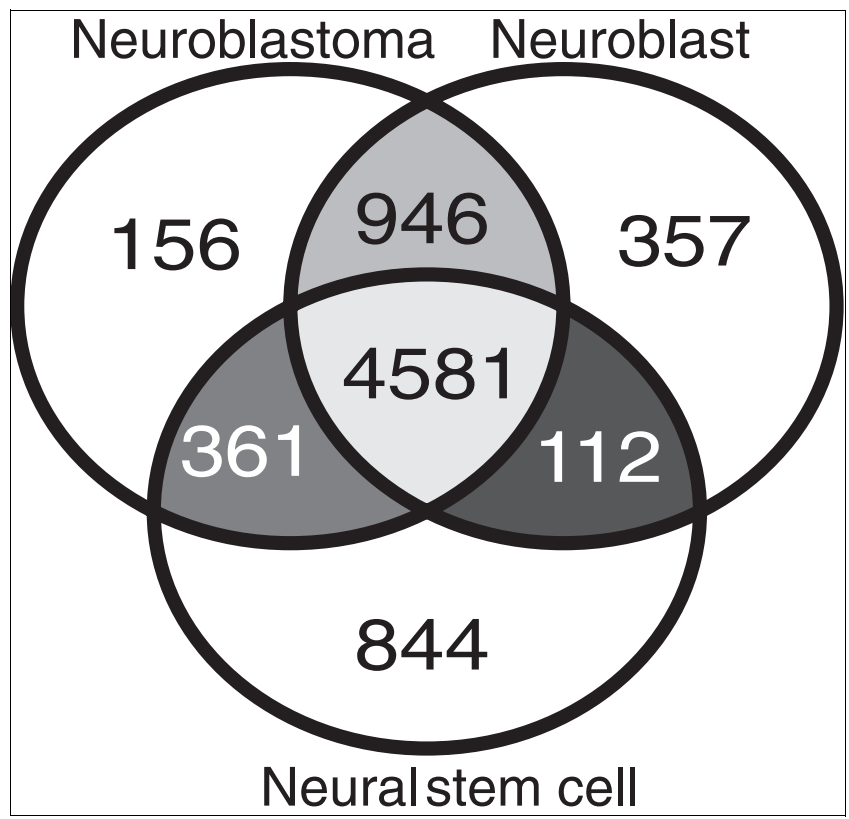

Figure 6

Venn diagram analysis of genes with detectable expression in neuroblast, neuroblastoma, and neural stem cell lines. This analysis shows that neuroblasts have many genes in common with neuroblastoma, but it also demonstrates that neural stem cell lines have more genes in common with the neuroblastomas than with the normal neuroblasts.

compared with neuroblasts, whereas 41 out of the 101 genes that are more highly expressed in unfavorable tumors exhibit differential expression compared with the neuroblasts (Table 4).

From this analysis, a few putative positional tumor suppressor candidates emerge: $C D C_{42}$ on 1p36, CACNA2D3 on 3p21, and $D L K 1$ on $14 \mathrm{q}$. The latter two genes are of particular inter- 
Table 3

Differentially expressed transcription factors, neurogenesis, and apoptosis genes

\begin{tabular}{|c|c|c|c|c|c|c|}
\hline & \multicolumn{2}{|c|}{ Transcription factor (GO:0003700) } & \multicolumn{2}{|c|}{ Neurogenesis (GO:0007399) } & \multicolumn{2}{|c|}{ Apoptosis (GO:0006915) } \\
\hline & Gene name & Location & Gene name & Location & Gene name & Location \\
\hline \multirow[t]{4}{*}{ Neuroblast $>$ neuroblastoma } & MLL & $11 \mathrm{q}$ & APOE & $19 q$ & APOE & $19 q$ \\
\hline & NROBI & $X_{p}$ & GREMI & $15 q$ & PLAGLI & $6 q$ \\
\hline & RORA & $15 q$ & TFAP2B & $6 p$ & SCARBI & $12 q$ \\
\hline & TFAP2B & $6 p$ & & & TDGFI & $3 p$ \\
\hline \multirow[t]{23}{*}{ Neuroblast $<$ neuroblastoma } & ASCLI* & $12 q$ & $A L K$ & $2 p$ & $B C L 2$ & $18 q$ \\
\hline & ATF3 & lq & APBB2 & $4 p$ & BCLAFI & $6 q$ \\
\hline & CNOT7 & $8 p$ & ASCLI & $12 q$ & BIRC5 & $17 q$ \\
\hline & CUTL2 & $12 q$ & CDK5RI & $17 q$ & $C C L 2$ & $17 q$ \\
\hline & ETV6 & $12 p$ & FEZI & 119 & CD2 & Ip \\
\hline & $\mathrm{FOXCl}$ & $6 p$ & GPI & $19 q$ & CD74 & $5 q$ \\
\hline & HCLSI & $3 q$ & INHBA & $7 p$ & CIAPINI & $16 q$ \\
\hline & IRF8 & $16 q$ & LARGE & $22 q$ & CYCS & $7 p$ \\
\hline & KLFIO & $8 q$ & MBNLI & $3 q$ & HTRA2 & $2 p$ \\
\hline & $M L X$ & $17 q$ & NEFH & $22 q$ & IER3 & $6 p$ \\
\hline & NFE2LI & $17 q$ & NTRK3 & $15 q$ & IGFBP3 & $7 p$ \\
\hline & NFIB & $9 p$ & OLFMI & $9 q$ & INHBA & $7 p$ \\
\hline & NME2 & $17 q$ & PPTI & Ip & ITGB2 & $21 \mathrm{q}$ \\
\hline & RUNXI & $21 \mathrm{q}$ & SERPINFI & $17 p$ & ITGB3BP & Ip \\
\hline & SIX3 & $2 p$ & SIX3 & $2 p$ & LGALSI & $22 q$ \\
\hline & STATI & $2 q$ & SLITI & $10 q$ & LY86 & $6 p$ \\
\hline & STAT3 & $17 q$ & soxil & $2 p$ & OPAI & $3 q$ \\
\hline & TAFIO & $11 \mathrm{p}$ & STAT3 & $17 q$ & PRKCA & $17 q$ \\
\hline & TAF7 & $5 q$ & TRAPPC4 & 119 & RNFI30 & $5 q$ \\
\hline & TFDPI & $13 q$ & & & STATI & $2 q$ \\
\hline & TRIM22 & $11 \mathrm{p}$ & & & SULFI & $8 q$ \\
\hline & TSC22DI & $13 q$ & & & TNFRSF2I & $6 p$ \\
\hline & ZNF9I & $19 p$ & & & TUBB & $6 p$ \\
\hline
\end{tabular}

Shown are differentially expressed genes in neuroblastoma versus neuroblasts that belong to GO terms transcription factor, neurogenesis, and/or apoptosis, with an indication of the chromosomal localization. GO, Gene Ontology.

est because they are highly expressed in neuroblasts and favorable neuroblastomas, and their expression is significantly lower in unfavorable neuroblastomas. Among the genes that are more highly expressed in unfavorable neuroblastomas than in favorable ones and neuroblasts, the proven oncogenic transcription factor $M Y C N$ emerges (and putative downstream genes KIFAP3, OPHN1, RGS7, ODC1, TOP2A, TWIST1 and TYMS, according to NBGS), as do several other genes that have been identified or studied within the context of neuroblastomas such as $A L K$ and PRAME, and positional candidates on 17q including $B_{R} C_{5}, R N U 2$ and TOP2A.

\section{Expression of neurogenesis markers in neuroblasts and developmental origin of neuroblastoma}

Although this was not the primary aim of the present work, the neuroblast expression profile provides a unique resource for the investigation of gene expression in human sympathoadrenal progenitors. In a first attempt, we made an inventory of the genes that belong to the neurogenesis GO class, or that have been described to play a role in neural crest formation and migration, or that have proneural activity (Additional data file 4). This analysis showed that human fetal neuroblasts of 19 weeks' gestational age expressed 174 of the 359 genes in the neurogenesis GO class, and 26 of 89 proneural genes and genes involved in neural crest formation/migration.

To obtain possible clues on the developmental origin of neuroblastoma we compared the expression profiles of the neuroblastoma tumors with those of normal neuroblasts and neural stem cell cultures. Intersectional Venn diagram analysis of expressed genes shows that neuroblastomas have many genes in common with neuroblasts, as already shown above (Figure 6). Interestingly, when compared with neuroblasts, the neuroblastomas have more genes in common with the self-renewing neural stem cells (535 versus 145), among others the neurogenesis genes ASCL1, GSS, $S_{T A T}, U T P 11 L, E N A H, A P B B 2, C D K 5 R A P 2$, and LARGE. 
Table 4

Genes that are differentially expressed in favorable vs. unfavorable neuroblastoma

\begin{tabular}{|c|c|c|c|c|c|}
\hline \multicolumn{2}{|c|}{ Favorable NB > unfavorable NB } & NBGS & \multicolumn{2}{|c|}{ Favorable NB $<$ unfavorable NB } & NBGS \\
\hline \multicolumn{3}{|c|}{ neuroblast $<$ favorable NB } & \multicolumn{3}{|c|}{ neuroblast $<$ favorable NB, neuroblast $<$ unfavorable NB } \\
\hline AKAP7 & $6 q$ & - & FABP6 & $5 q$ & - \\
\hline ARL7 & $2 q$ & - & NEFL & $8 p$ & - \\
\hline ASPN & $9 q$ & - & NPY & $7 p$ & - \\
\hline$B C L 2$ & $18 q$ & 1 & \multicolumn{3}{|c|}{ neuroblast < unfavorable NB } \\
\hline C2orf23 & $2 p$ & - & ALK & $2 p$ & - \\
\hline CALBI & $8 q$ & - & ASCLI & $12 q$ & 1 \\
\hline CAMK2B & $7 p$ & 2 & BIRC5 & $17 q$ & 3 \\
\hline CD24 & $6 q$ & - & C22orfl 18 & $22 q$ & - \\
\hline CDC42 & Ip & 1 & C3 & $19 p$ & - \\
\hline DDAHI & Ip & - & CALCB & $\mathrm{IIP}$ & - \\
\hline DNAPTP6 & $2 q$ & - & CCNBI & $5 q$ & 1 \\
\hline EPB4 IL3 & $18 p$ & 1 & $C D 74$ & $5 q$ & - \\
\hline FAM70A & $\mathrm{Xq}$ & - & $\mathrm{CRH}$ & $8 q$ & - \\
\hline KIFAP3 & $\mathrm{Iq}$ & 1 & CSPG3 & $19 p$ & - \\
\hline OPHNI & $X q$ & - & DNCII & $7 q$ & - \\
\hline PDLIM5 & $4 q$ & - & DTL & 1 & 1 \\
\hline PPAN & $19 p$ & - & $F / 2$ & $5 q$ & - \\
\hline PRKCBI & $16 p$ & 1 & GFRA2 & $8 p$ & - \\
\hline RGS7 & $\mathrm{Iq}$ & 2 & IGHG3 & $14 q$ & - \\
\hline RNFII & Ip & - & $I G H M$ & $14 q$ & - \\
\hline ST6GALNAC5 & Ip & - & $I G K C$ & $2 p$ & 1 \\
\hline$S V 2 C$ & $5 q$ & - & IGLC2 & $22 q$ & - \\
\hline \multicolumn{3}{|c|}{ neuroblast $>$ favorable NB, neuroblast $>$ unfavorable NB } & LMO3 & $12 p$ & 1 \\
\hline CACNA2D3 & $3 p$ & - & MGC27I65 & $14 q$ & - \\
\hline DLKI & $14 q$ & 2 & MLFIIP & $4 q$ & 1 \\
\hline$H B G I$ & $11 \mathrm{p}$ & - & MMP9 & $20 q$ & 1 \\
\hline HBG2 & $11 \mathrm{p}$ & - & MYCN & $2 p$ & 9 \\
\hline \multicolumn{3}{|c|}{ neuroblast $>$ unfavorable NB } & \multicolumn{3}{|l|}{ NEFH } \\
\hline$A L D H 3 A 2$ & $17 p$ & 1 & $O D C l$ & $2 p$ & 3 \\
\hline DLCl & $8 p$ & - & OGDHL & $10 q$ & - \\
\hline EYAI & $8 q$ & - & $P 2 R \times 5$ & $17 p$ & - \\
\hline $\mathrm{GCHI}$ & $14 q$ & 1 & PRAME & $22 q$ & 1 \\
\hline HBA2 & $16 p$ & - & RPS4YI & $Y_{p}$ & 1 \\
\hline KIAA0960 & $7 p$ & I & SERPINFI & $17 p$ & - \\
\hline PTPRD & $9 p$ & - & TNFRSFIOB & $8 p$ & 2 \\
\hline PTPRK & $6 q$ & - & TOP2A & $17 q$ & 1 \\
\hline SLCI8AI & $8 p$ & - & TWISTI & $7 p$ & 1 \\
\hline TFAP2B & $6 p$ & - & TYMS & $18 p$ & - \\
\hline \multirow[t]{3}{*}{ TLN2 } & $15 q$ & 1 & XAGEI & $X p$ & - \\
\hline & & & \multicolumn{3}{|c|}{ neuroblast $>$ favorable NB, neuroblast $<$ unfavorable NB } \\
\hline & & & IGLJ3 & $22 q$ & 1 \\
\hline
\end{tabular}


neuroblast $>$ favorable NB

\begin{tabular}{lcl}
\hline$R N U 2$ & $17 \mathrm{q}$ & - \\
\hline neuroblast $>$ favorable NB, neuroblast $>$ unfavorable NB \\
\hline LOC492304 $\quad 11 \mathrm{P}$
\end{tabular}

Genes that are differentially expressed compared with neuroblasts among the differentially expressed genes in favorable neuroblastoma (NB) versus unfavorable neuroblastoma, with an indication of the number of neuroblastoma microarray studies in which these genes were found through NBGS analysis. NBGS, Neuroblastoma Gene Server.

\section{Discussion}

Comparison of the mRNA expression repertoire of cancer with that of their normal counterpart cells is a commonly applied strategy to elucidate the development and pathophysiology of the cancer type under study. For pediatric neuroblastoma, fetal adrenal sympathetic neuroblasts are assumed to be the cells of origin, but these cells are virtually absent after birth and thus not readily accessible for analysis [8]. In this study we were able, for the first time, to determine the expression profile of microdissected islets of fetal sympathetic neuroblasts, providing an important landmark for comparative expression analysis. In parallel, adjacent cortex cells and carefully selected representative neuroblastoma tumors were profiled for data mining purposes. Our main goals were to provide support for the cell of origin hypothesis of neuroblastoma, and to obtain preliminary insights into the disrupted cellular circuitry that is involved in neuroblastoma pathogenesis.

Quality assessment and biologic validation of the established neuroblast expression profile demonstrated that the proper cells were isolated and that their expression profiles are trustworthy. Next, we assessed the cell of origin hypothesis for neuroblastomas. To this end, the transcriptional profile of the neuroblasts was thoroughly compared with those of neuroblastoma tumors and normal tissues. These analyses confirmed that neuroblast and neuroblastoma cells indeed present with highly similar expression profiles. These exploratory findings provide, for the first time, molecular support for the cell of origin hypothesis. Also, they reinforce our assumption that the neuroblast gene expression profile constitutes a valid tool for further data mining of neuroblastoma gene expression patterns.

Following initial data validation and assessment of the cell of origin hypothesis, we performed a series of data mining analyses aimed at identifying genes and pathways that may be involved in neuroblastoma oncogenesis and tumor biology. In a first step, the neuroblastoma tumor expression profile was compared with that of the neuroblasts, yielding 71 genes with higher expression in neuroblasts and 565 genes with increased expression in neuroblastoma. We subjected these gene lists to a novel meta-analytical approach that allowed comparison with 25 published neuroblastoma gene lists and facilitated the detection of genes identified in at least one other microarray study. Furthermore, we performed GO analysis and we used a new approach to positional mapping of the differentially expressed genes. In a second step, following analysis of combined tumors, we sought genes differentially expressed in carefully selected representative cases of favorable and unfavorable neuroblastomas and further analyzed the expression of these genes in neuroblasts. This approach yielded 37 and 41 genes, respectively.

When combining the data from the above analyses, it was apparent that many of the genes previously reported in the context of neuroblastoma had been identified, thus underscoring the validity of our data mining approach. These included MYCN, MYCN co-amplified genes such as $D D X 1$, known MYCN target genes such as $O D C 1$ and $M C M 7$, and prognostic markers (MYCN, NTRK1, and CD44), as well as various other genes such as $A S C L 1, A L K, B C L 2, B I R C 5, D L K 1$, $N M E 1, N M E 2$ and $N T R K_{3}$ that have previously been mentioned or studied within the context of neuroblastoma. For some genes only circumstantial evidence for a role in neuroblastoma is present (WSB1, CDC42, PLAGL1, PRAME and TGFBR 3); that we identified these genes in the present study warrants further investigations into their possible role in neuroblastoma development. Finally, several genes, for which no evidence of involvement in neuroblastoma development has yet been obtained, emerged for the first time from our analyses. These include $S T A T_{3}, I G S F_{4}$ and $C A C N A 2 D_{3}$, and they should also be studied in further detail to determine their possible role in neuroblastoma pathogenesis.

Although the present study is just a first step in a new strategy of data mining of neuroblastoma gene expression profiles, we nevertheless obtained new information that is particularly interesting for the $17 \mathrm{q}$ region. Gain of distal $17 \mathrm{q}$ is not only the most frequent chromosomal alteration in high stage neuroblastoma but it is also the strongest independent adverse prognostic genetic factor [21,22]. However, no func- 
Table 5

\begin{tabular}{|c|c|c|c|c|c|c|c|c|c|c|}
\hline Sample number & Lab number & $\%$ Tumor cells & Stage & MYCN amp & Ploidy & $\begin{array}{l}\text { Adrenal } \\
\text { localisation }\end{array}$ & Age & Dead/alive & $\begin{array}{l}\text { Overall survival } \\
\text { (months) }\end{array}$ & Type \\
\hline NBI & $01 T 15$ & 80 & $4 S$ & No & Tri & Yes & $<$ I year & Alive & 61.4 & Favorable \\
\hline NB2 & $98 T 33$ & 95 & 1 & No & Tri & Yes & < I year & Alive & 76.9 & Favorable \\
\hline NB3 & $96 \mathrm{~T} 82$ & 90 & I & No & Tri & Yes & < I year & Alive & 115.5 & Favorable \\
\hline NB4 & $99 T 129$ & 90 & 1 & No & Tri & Yes & < I year & Alive & 71.7 & Favorable \\
\hline NB5 & $01 T 28$ & 90 & 4 & Yes & $\mathrm{Di}$ & Yes & > I year & Dead & 5.6 & Unfavorable \\
\hline NB6 & 03T304 & 100 & $3^{a}$ & No & $\mathrm{Di}$ & Abdominal & $>$ I year & Alive & 12.0 & Unfavorable \\
\hline NB7 & $03 T 236$ & 90 & 4 & No & ND & Yes & $>5$ year & Dead & 19.4 & Unfavorable \\
\hline NB8 & 00T54 & 70 & I & No & Tri & Yes & $<$ I year & Alive & 62.6 & Favorable \\
\hline NB9 & 00T35 & $>95$ & 4 & Yes & $\mathrm{Di}$ & Yes & $<$ I year & Dead & 13.7 & Unfavorable \\
\hline NBIO & 99TI25 & 80 & 3 & No & $\mathrm{Di}$ & Yes & $>5$ year & Alive & 79.3 & Unfavorable \\
\hline NBII & $92 \mathrm{~W} 145$ & 70 & 4 & No & ND & ND & $>5$ year & Dead & 19.5 & Unfavorable \\
\hline $\mathrm{NB} 12$ & $02 T 192$ & 100 & 4 & Yes & $\mathrm{Di}$ & Abdominal & $>5$ year & Dead & 16.2 & Unfavorable \\
\hline NBI 3 & D03I & $>95$ & 4 & No & $\mathrm{Di}$ & Abdominal & > I year & Dead & 64.8 & Unfavorable \\
\hline NBI 4 & E002 & $>80$ & 4 & No & ND & Abdominal & $>$ I year & Alive & 65.7 & Unfavorable \\
\hline NBI5 & E037 & $>80$ & 4 & No & ND & Abdominal & > I year & Alive & 45.3 & Unfavorable \\
\hline NBI 6 & E044 & $>80$ & 4 & No & ND & Yes & $<$ I year & Alive & 37.0 & Unfavorable \\
\hline NBI7 & EI2I & $>80$ & 4 & Yes & ND & Abdominal & $>$ I year & Dead & 78.4 & Unfavorable \\
\hline NBI 8 & $04 T 121$ & 60 & 3 & Yes & $\mathrm{Di}$ & Yes & $>$ I year & Dead & 6 & Unfavorable \\
\hline
\end{tabular}

Based on stage, MYCN amplification, ploidy, and age at diagnosis, samples were subdivided into favorable or unfavorable type.

aNeuroblastoma or ganglioneuroblastoma. ND, not determined or unknown.

tional evidence has been provided for a specific role of $17 \mathrm{q}$ genes in neuroblastoma development. A major obstacle is the difficulty in refining the critical region for $17 q$ gain that, as a consequence, has remained very large, hampering selection of functional candidates. Based on recent high-resolution array-CGH (comparative genome hybridization) profiling of 17q breakpoints leading to gain for distal 17q, we have proposed the hypothesis that the critical region for $17 \mathrm{q}$ gain is located within a $5 \mathrm{Mb}$ segment on 17q21.32-q22, immediately distal to the most distal breakpoint (Vandesompele and coworkers, unpublished data).

To substantiate this hypothesis, we performed positional gene enrichment analysis on chromosome 17 for the genes that are more highly expressed in neuroblastoma compared to neuroblast. Interestingly, this yielded a highly significant enrichment for two loci on the long arm of chromosome 17, including the above mentioned region, further demonstrating the high likelihood of the presence of a neuroblastoma dosage sensitive gene. A total of 11 differentially expressed genes are contained within this 17q21.3 segment, including NME1 and $N M E 2$. The role of the latter two genes in cancer is controversial, but once again these genes emerge from a neuroblastoma study. Among the genes that are more highly expressed in neuroblastoma, another interesting candidate was found to be located just outside the enriched 17q21.3 segment but within the same chromosome band, namely STAT3. This gene encodes an oncogenic transcription factor that plays a central role in the janus kinase (JAK)-signal transducer and activator of transcription (STAT) signaling pathway, promoting growth and survival of tumor cells, inducing tumor angiogenesis, and suppressing antitumor immune responses. Of particular interest is that $S_{T A T}$ is also implicated in neurogenesis. Given their documented role in cancer, STAT proteins have been shown to be promising molecular targets for novel cancer therapies, including small molecule inhibitors of STAT signaling. The finding of increased STAT3 expression might also be of relevance in the light of the observed $A L K$ overexpression in this and previous studies [23,24], because ALKis known to activate STAT3 by phosphorylation [25]. Suppression of activated ALK in neuroblastoma cells by RNA interference was shown to lead to rapid apoptosis [26].

Positional mapping of the genes that are expressed to a lesser degree in neuroblastomas than in neuroblasts yielded some remarkable positional tumor suppressor candidate genes. Among others, these include CASP9 and CDC42 (1p36), which have already been studied in neuroblastoma $[27,28]$; CACNA2D3 (3p21-p22), which was recently proposed as a tumor suppressor gene in lung cancer [29]; IGSF4 (11q23), which is a known tumor suppressor gene in several cancers; and DLK1 (14q). All of these genes have been mapped within or near to previously defined shortest regions of overlap for deletions in neuroblastoma and should therefore be considered for further functional studies.

Yet another interesting candidate neuroblastoma suppressor gene is WSB1. This gene was found in four published neuroblastoma microarray studies to be more highly expressed in favorable neuroblastomas. Moreover, WSB1 was very recently shown to be associated with prognosis [30]. Recent evidence indicated that WSB1 (WD repeat and SOCS box- 
containing 1) is part of an E3 ubiquitin ligase and that it exhibits similarity with an interchangeable F-box protein $\beta$ $\mathrm{TrCP} 1$ that is implicated in nuclear factor $-\kappa \mathrm{B}, \mathrm{Wnt} / \mathrm{Wingless}$, and hedgehog signaling pathways [31,32]. Together with other unpublished data on the possible implications of the Wnt pathway in neuroblastomas, we speculate that reduced ubiquitination of $\beta$-catenin caused by low levels of WSB1 expression in unfavorable neuroblastomas could lead to upregulation of several genes that are involved in cell proliferation [33].

Finally, PLAGL1 was identified as a candidate neuroblastoma tumor suppressor gene in the present study. This gene regulates apoptosis and cell cycle arrest and plays a role in the control of cell fate during neurogenesis [34]. PLAGL1 is localized on chromosome 6q24-q25, a region that is frequently deleted or epigenetically modified in many solid tumors [35], including neuroblastoma (unpublished data).

The dataset presented will also be of future value for the study of sympathetic nervous system development and the developmental stage from which neuroblastoma originates. Ideally, more neuroblast samples from different gestation times should be collected in order to gain broader insight. The present neuroblast collections offer a glimpse into this developmental process, as illustrated by the expression of ASCL1 and $D L K 1$. ASCL1 is a known early neurogenesis marker [36], which was confirmed by the observed expression in the immature self-renewing neural stem cells and the absence in the more mature neuroblasts. The significantly higher expression in part of the unfavorable neuroblastomas compared with the neuroblasts might denote an earlier stage of differentiation arrest or reflect a process of de-differentiation of the unfavorable neuroblastoma cells. $D L K 1$, on the other hand, is expressed to a lesser degree in the unfavorable neuroblastoma than in the favorable tumors and the neuroblast (in concordance with observations reported by Hsiao and coworkers [37]). Later in neural development, DLK1 (deltalike 1 homolog) downregulates ASCL1 (achaete-scute complex-like 1) through NOTCH (notch homolog), further inducing neuronal differentiation [38]. Hence, these expression differences indicate a different time point of developmental arrest for favorable and unfavorable neuroblastoma, as was previously suggested.

\section{Conclusion}

The inclusion of normal neuroblasts in gene expression analysis of malignant neuroblastomas was shown to add significant power to the identification of candidate neuroblastoma genes. Inclusion of larger sets of neuroblastoma tumors with well characterized genomic alterations and positional mapping of the genes in critically involved genomic regions in neuroblastomas will be crucial for tracing back the molecular basis of neuroblastoma.

\section{Materials and methods \\ Fetal and tumor material}

Ethical approval was obtained for the collection of fetal adrenal glands from fetuses aborted for clinical reasons (Ethics committee Erasme Hospital, Brussels, Belgium; approval no.: OMo21). The induced abortion was performed by prostaglandin instillation to the patient. The adrenals were removed during necropsy and snap-frozen in liquid nitrogen within 3 hours after delivery. Neuroblastoma tumors were collected in the Center for Medical Genetics (Ghent, Belgium; $n=12$ ), in the National Center for Medical Genetics (Dublin, Ireland; $n$ $=1$ ), and in the University Children's Hospital of Essen (Essen, Germany; $n=5$ ). For this study, we preferentially selected tumors that were localized in the adrenal gland (11/ 18). Based on INSS stage (international neuroblastoma staging system), MYCN status, ploidy and age at diagnosis, and for some cases pathologic rapports, samples were divided into favorable or unfavorable neuroblastoma (Table 5).

\section{Hematoxylin and eosin staining, immunohistochemistry, and laser capture microdissection}

Fetal adrenal glands were embedded in Tissue-Tek OCT compound (Sakura, Torrance, CA, USA). Immunohistochemical staining was performed as described previously [8]. For microdissection, cryosections were first stained with hematoxylin and eosin, and mounted in order to scan for neuroblast clusters. When neuroblast clusters were found, stained but unmounted cryosections were prepared for laser capture microdissection. Embedding, sectioning, staining, and laser capture microdissection of neuroblast clusters and surrounding cortex cells was performed as described previously [9].

\section{RNA isolation and quality assessment}

Microdissected cells were collected in RNA extraction buffer, followed by RNA extraction and DNase treatment on column (Qiagen, Venlo, Netherlands). RNA of the tumor samples was extracted using the RNeasy Mini kit (Qiagen), in accordance with the manufacturer's instructions. Four of the neuroblastoma tumor pieces were first mixed with Lysing Matrix D microbeads (Qbiogene, Illkirch, France) and $700 \mu \mathrm{l}$ RTL buffer (Qiagen), and homogenized using FastPrep FP220 (Qbiogene). A fraction of the RNA was used for cDNA synthesis after DNase treatment (described by Vandesompele and coworkers [39]). RNA quality was measured with the RNA Nano or Pico LabChip kit (Agilent, Diegem, Belgium) using 1 $\mu \mathrm{l}$ of the RNA isolates.

\section{Oligonucleotide chip analysis and data mining}

For each of the three fetal adrenal glands, the different neuroblast RNA isolates were pooled, amplified using a tworound labeling protocol, and hybridized to HG-U133A oligonucleotide chips (Affymetrix, Santa Clara, CA, USA), containing 18,400 transcripts including 14,500 well characterized human genes (protocol described previously [40]). The same amplification protocol was applied to RNA of three cortex 
samples and approximately 100 ng RNA of 18 neuroblastoma tumors. The homogeneity of the subgroups (neuroblast, cortex, favorable and unfavorable neuroblastoma) allowed us to use a limited number of samples for expression profiling. Several technical parameters demonstrate that the hybridization was of good quality (Additional data file 1(d)).

We obtained the raw data from the Genomics Institute of the Novartis Foundation compendium of normal tissues consisting of 79 normal tissues assayed in duplicate using the Affymetrix HG-U133A array [12]. Raw HG-U133A Affymetrix array data from three neural stem cells were kindly provided by Wright and coworkers [13].

CEL files were loaded in the R-Bioconductor (BioC) software and normalized with the Robust Multi Chip Average (RMA) method [41]. Identification of differentially expressed genes for pairwise comparisons were performed using the RankProd R-package, which is based on the Rank Product principle [10]. We used the GoHyperG function from the BioC project to find over-represented biologic process GO categories from the gene lists using hypergeometric test for significance. KEGG pathway analysis was performed with the Webgestalt web interface using hypergeometric test for significance [42].

Meta-analyses of published neuroblastoma microarray data were performed with the NBGS (see Additional data fiile 3 for detailed information).

Positional gene enrichment analysis was performed with inhouse developed R-Bioconductor script PGE (De Preter and coworkers, unpublished data) [15]. PGE scans the entire genome using a moving window with a user-defined width (5 $\mathrm{Mb}$ ) and step size (1 Mb). In each window, the $-10 \log (\mathrm{p})$ of the Fisher Exact Test is calculated. This test was used to investigate whether there is an association between the gene list and a particular chromosomal region (the window under investigation). As such, it will identify regions that contain more (or less) genes in the gene list than expected by chance. The (known) unequal distribution of the genes along the chromosomes is taken into account, because the number of genes from the list that are located in the region is compared with the total number of genes in that particular region. Correction for multiple testing is performed using the false discovery rate method of Benjamini and Hochberg [43], using the R-multtest package.

Expression microarray data were submitted to ArrayExpress [44], accession number E-MEXP-669.

\section{Additional data files}

The following additional data are available with the online version of this paper. Additional data file 1 includes documents on RNA quality and quantity measures, validation of
Affymetrix chip results, and Affymetrix chip quality parameters [39,45-49]. Additional data file 2 lists genes that are differentially expressed in neuroblast versus cortex samples, in neuroblast versus favorable (F) and/or unfavorable (UF) neuroblastoma, and in favorable versus unfavorable neuroblastoma (identified using Rank Product algorithm). Additional data file 3 provides results of NBGS analysis of the genes that are differentially expressed between neuroblasts and (favorable and/or unfavorable) neuroblastomas (gene lists in Additional data file 1). Additional data file 4 lists the genes of GO class neurogenesis and proneural genes that are expressed in neuroblast samples ( $>36$ th percentile) [50-54].

\section{Authors' contributions}

KDP performed the neuroblast microdissection and microarray data mining, and drafted the paper. $\mathrm{PH}$ collected the fetal adrenal glands and helped with the neuroblast microdissection. NY helped with microdissection, RNA isolation and quantification, RNA quality control and real-time quantitative polymerase chain reaction validation experiments. SB performed the immunohistochemical stainings that were reviewed and discussed by SP. AS, AE, RS, MR, YB, and GL collected neuroblastoma tumor samples. JV and FS participated in the study's design and coordination. All authors have reviewed the manuscript, and FS and ADP were the final editors of the manuscript.

\section{Acknowledgements}

We would like to thank Ann Neesen and Indra Deborle (Department of Pneumology, Ghent University Hospital, Belgium) for their help with the preparation of the cryo-sections.

This text presents research results of the Belgian program of Interuniversity Poles of Attraction initiated by the Belgian State, Prime Minister's Office, Science Policy Programming. Katleen De Preter is supported by a post-doctoral grant from the Institute for the Promotion of Innovation by Science and Technology in Flanders (IWT). Jo Vandesompele is post-doctoral researcher with a grant of the Fund for Scientific Research Flanders. This work was supported by the 'Kinderkankerfonds', the Fund for Scientific Research Flanders ('Krediet aan Navorsers' J.V. I.5.243.05 and K.D.P. I.5.I I7.06), FWO-grant G.0028.00 and GOA-grant I 205 I 203.

\section{References}

I. Trochet D, Bourdeaut F, Janoueix-Lerosey I, Deville A, De Pontual L, Schleiermacher G, Coze C, Philip N, Frebourg T, Munnich A, et al: Germline Mutations of the Paired-Like Homeobox 2B (PHOX2B) Gene in Neuroblastoma. Am J Hum Genet 2004, 74(4):76I-764.

2. Weiss WA, Aldape K, Mohapatra G, Feuerstein BG, Bishop JM: Targeted expression of MYCN causes neuroblastoma in transgenic mice. Embo J 1997, I6(I I):2985-2995.

3. Berwanger B, Hartmann O, Bergmann E, Bernard S, Nielsen D, Krause M, Kartal A, Flynn D, Wiedemeyer R, Schwab M, et al.: Loss of a FYN-regulated differentiation and growth arrest pathway in advanced stage neuroblastoma. Cancer Cell 2002, 2(5):377-386

4. McArdle L, McDermott M, Purcell R, Grehan D, O'Meara A, Breatnach F, Catchpoole D, Culhane AC, Jeffery I, Gallagher WM, et al: Oligonucleotide microarray analysis of gene expression in neuroblastoma displaying loss of chromosome II q. Carcino- 
genesis 2004.

5. Wang Q, Diskin S, Rappaport E, Attiyeh E, Mosse Y, Shue D, Seiser E, Jagannathan J, Shusterman S, Bansal M, et al.: Integrative genomics identifies distinct molecular classes of neuroblastoma and shows that multiple genes are targeted by regional alterations in DNA copy number. Cancer research 2006, 66( I 2):6050-6062

6. Pahlman S, Hedborg F: Development of the neural crest and sympathetic nervous system. In Neuroblastoma First edition. Edited by: Brodeur GM, Sawada T, Tsuchida Y, Voute PA. Amsterdam: Elsevier; 2000:9-19.

7. Hoehner IC, Gestblom C, Hedborg F, Sandstedt B, Olsen L, Pahlman $S$ : A developmental model of neuroblastoma: differentiating stroma-poor tumors' progress along an extra-adrenal chromaffin lineage. Lab Invest 1996, 75(5):659-675.

8. Hoehner JC, Hedborg F, Eriksson L, Sandstedt B, Grimelius L, Olsen L, Pahlman S: Developmental gene expression of sympathetic nervous system tumors reflects their histogenesis. Lab Invest 1998, 78(I):29-45

9. De Preter K, Vandesompele J, Heimann P, Kockx MM, Van Gele M Hoebeeck J, De Smet E, Demarche M, Laureys G, Van Roy N, et al.: Application of laser capture microdissection in genetic analysis of neuroblastoma and neuroblastoma precursor cells. Cancer Lett 2003, I97( I-2):53-6I.

10. Breitling R, Armengaud P, Amtmann A, Herzyk P: Rank products: a simple, yet powerful, new method to detect differentially regulated genes in replicated microarray experiments. FEBS Lett 2004, 573(1-3):83-92.

II. Baird K, Davis S, Antonescu CR, Harper UL, Walker RL, Chen Y, Glatfelter AA, Duray PH, Meltzer PS: Gene expression profiling of human sarcomas: insights into sarcoma biology. Cancer Res 2005, 65(20):9226-9235

12. Su Al, Wiltshire T, Batalov S, Lapp H, Ching KA, Block D, Zhang J, Soden R, Hayakawa M, Kreiman G, et al:: A gene atlas of the mouse and human protein-encoding transcriptomes. Proc Natl Acad Sci USA 2004, I 0 I ( I 6):6062-6067.

13. Wright LS, Li J, Caldwell MA, Wallace K, Johnson JA, Svendsen CN: Gene expression in human neural stem cells: effects of leukemia inhibitory factor. J Neurochem 2003, 86(I): I79-195.

14. Lastowska M, Cotterill S, Bown N, Cullinane C, Variend S, Lunec J, Strachan T, Pearson AD, Jackson MS: Breakpoint position on I 7q identifies the most aggressive neuroblastoma tumors. Genes Chromosomes Cancer 2002, 34(4):428-436.

I5. Positional Gene Enrichment (PGE) [http://medgen.ugent.be/ PGE]

16. Hoebeeck J, Michels E, Menten B, Van Roy N, Eggert A, Schramm A, De Preter K, Yigit N, De Smet E, De Paepe A, et al.: High resolution tiling path BAC array deletion mapping suggests commonly involved 3p21-p22 tumor suppressor genes in neuroblastoma and more frequent tumors. Int / Cancer in press.

17. Guo C, White PS, Weiss MJ, Hogarty MD, Thompson PM, Stram DO Gerbing R, Matthay KK, Seeger RC, Brodeur GM, et al.: Allelic deletion at I/q23 is common in MYCN single copy neuroblastomas. Oncogene 1999, I 8(35):4948-4957.

18. Maris JM, Guo C, White PS, Hogarty MD, Thompson PM, Stram DO Gerbing R, Matthay KK, Seeger RC, Brodeur GM: Allelic deletion at chromosome bands $\mathrm{IIql4-23}$ is common in neuroblastoma. Med Pediatr Oncol 200I, 36(I):24-27.

19. Mosse Y, Greshock J, King A, Khazi D, Weber BL, Maris JM: Identification and high-resolution mapping of a constitutional I I q deletion in an infant with multifocal neuroblastoma. Lancet Oncol 2003, 4( I 2):769-77I.

20. Hoshi M, Otagiri N, Shiwaku HO, Asakawa S, Shimizu N, Kaneko Y, Ohi R, Hayashi Y, Horii A: Detailed deletion mapping of chromosome band $14 q 32$ in human neuroblastoma defines a I.IMb region of common allelic loss. Br J Cancer 2000, 82(I I): $1801-1807$

21. Bown N, Cotterill S, Lastowska M, O'Neill S, Pearson AD, Plantaz D, Meddeb M, Danglot G, Brinkschmidt C, Christiansen H, et al.: Gain of chromosome arm $\mathbf{~ I q}$ and adverse outcome in patients with neuroblastoma. N Engl J Med I999, 340(25): |954-|96|.

22. Vandesompele J, Baudis M, De Preter K, Van Roy N, Ambros P, Bown $\mathrm{N}$, Brinkschmidt C, Christiansen $\mathrm{H}$, Combaret V, Lastowska M, et al.: Unequivocal delineation of clinicogenetic subgroups and development of a new model for improved outcome prediction in neuroblastoma. J Clin Oncol 2005, 23( I 0):2280-2299.

23. Lamant L, Pulford K, Bischof D, Morris SW, Mason DY, Delsol G, Mariame B: Expression of the ALK tyrosine kinase gene in neuroblastoma. Am I Pathol 2000, I56(5): I7| I-I72I.

24. Miyake I, Hakomori Y, Shinohara A, Gamou T, Saito M, Iwamatsu A, Sakai R: Activation of anaplastic lymphoma kinase is responsible for hyperphosphorylation of ShcC in neuroblastoma cell lines. Oncogene 2002, 2 I (38):5823-5834.

25. Zamo A, Chiarle R, Piva R, Howes J, Fan Y, Chilosi M, Levy DE, Inghirami G: Anaplastic lymphoma kinase (ALK) activates Stat3 and protects hematopoietic cells from cell death. Oncogene 2002, 2 I (7): I038-1047.

26. Osajima-Hakomori Y, Miyake I, Ohira M, Nakagawara A, Nakagawa A, Sakai R: Biological role of anaplastic lymphoma kinase in neuroblastoma. Am J Pathol 2005, I67(I):213-222.

27. Teitz T, Wei T, Liu D, Valentine V, Valentine M, Grenet J, Lahti JM, Kidd VJ: Caspase-9 and Apaf-I are expressed and functionally active in human neuroblastoma tumor cell lines with I 36 LOH and amplified MYCN. Oncogene 2002, 2 I (I 2): |848-|858.

28. Valentijn LJ, Koppen A, van Asperen R, Root HA, Haneveld F, Versteeg R: Inhibition of a new differentiation pathway in neuroblastoma by copy number defects of $\mathrm{N}$-myc, Cdc42, and nm23 genes. Cancer Res 2005, 65(8):3।36-3।45.

29. Tai AL, Mak W, Ng PK, Chua DT, Ng MY, Fu L, Chu KK, Fang Y, Qiang Song $Y$, Chen M, et al.: High-throughput loss-of-heterozygosity study of chromosome 3 p in lung cancer using singlenucleotide polymorphism markers. Cancer Res 2006 , 66(8):4I33-4I38.

30. Chen QR, Bilke S, Wei JS, Greer BT, Steinberg SM, Westermann F, Schwab M, Khan J: Increased WSB I copy number correlates with its over-expression which associates with increased survival in neuroblastoma. Genes, chromosomes \& cancer 2006, 45(9):856-862

3I. Dentice M, Bandyopadhyay A, Gereben B, Callebaut I, Christoffolete MA, Kim BW, Nissim S, Mornon JP, Zavacki AM, Zeold A, et al.: The Hedgehog-inducible ubiquitin ligase subunit WSB-I modulates thyroid hormone activation and PTHrP secretion in the developing growth plate. Nat Cell Biol 2005, 7(7):698-705.

32. Maniatis T: A ubiquitin ligase complex essential for the NF. kappaB, Wnt/Wingless, and Hedgehog signaling pathways. Genes Dev 1999, I3(5):505-510

33. Nakayama KI, Nakayama K: Ubiquitin ligases: cell-cycle control and cancer. Nat Rev Cancer 2006, 6(5):369-38I.

34. Valente T, Auladell C: Expression pattern of Zacl mouse gene, a new zinc-finger protein that regulates apoptosis and cellular cycle arrest, in both adult brain and along development. Mech Dev 200I, I 08( I-2):207-2I I.

35. Abdollahi A, Pisarcik D, Roberts D, Weinstein J, Cairns $P$, Hamilton TC: LOTI (PLAGLI/ZACI), the candidate tumor suppressor gene at chromosome 6q24-25, is epigenetically regulated in cancer. I Biol Chem 2003, 278(8):604l-6049.

36. Gestblom C, Grynfeld A, Ora I, Ortoft E, Larsson C, Axelson H, Sandstedt B, Cserjesi P, Olson EN, Pahlman S: The basic helix-loophelix transcription factor dHAND, a marker gene for the developing human sympathetic nervous system, is expressed in both high- and low-stage neuroblastomas. Lab Invest 1999 , 79(I):67-79.

37. Hsiao CC, Huang CC, Sheen JM, Tai MH, Chen CM, Huang LL, Chuang JH: Differential expression of delta-like gene and protein in neuroblastoma, ganglioneuroblastoma and ganglioneuroma. Mod Pathol 2005, I 8(5):656-662.

38. Pahlman S, Stockhausen MT, Fredlund $E$, Axelson $\mathrm{H}$ : Notch signaling in neuroblastoma. Semin Cancer Biol 2004, I4(5):365-373.

39. Vandesompele J, De Paepe A, Speleman F: Elimination of primerdimer artifacts and genomic coamplification using a twostep SYBR green I real-time RT-PCR. Anal Biochem 2002 303(I):95-98.

40. Bruder D, Probst-Kepper M, Westendorf AM, Geffers R, Beissert S, Loser K, von Boehmer H, Buer J, Hansen W: Neuropilin-I: a surface marker of regulatory $T$ cells. Eur I Immunol 2004, 34(3):623-630.

4I. Bolstad BM, Irizarry RA, Astrand M, Speed TP: A comparison of normalization methods for high density oligonucleotide array data based on variance and bias. Bioinformatics 2003 , I 9(2): 185-193.

42. Zhang B, Kirov S, Snoddy J: WebGestalt: an integrated system for exploring gene sets in various biological contexts. Nucleic Acids Res 2005:W74I-748.

43. Benjamini $Y$, Hochberg $Y$ : Controlling the false discovery rate: a practical and powerful approach to multiple testing. J $R$ Sta tisit Soc 1995, B 57:289-300. 
44. ArrayExpress [http://www.ebi.ac.uk/arrayexpress/]

45. Auer H, Lyianarachchi S, Newsom D, Klisovic MI, Marcucci G, Kornacker K, Marcucci U: Chipping away at the chip bias: RNA degradation in microarray analysis. Nat Genet 2003, 35(4):292-293.

46. Luzzi V, Mahadevappa M, Raja R, Warrington JA, Watson MA: Accurate and reproducible gene expression profiles from laser capture microdissection, transcript amplification, and high density oligonucleotide microarray analysis. J Mol Diagn 2003, 5(I):9-14.

47. Pattyn F, Speleman F, De Paepe A, Vandesompele J: RTPrimerDB: the real-time PCR primer and probe database. Nucleic Acids Res 2003, 3 I(I): I22-I23.

48. Schoor O, Weinschenk T, Hennenlotter J, Corvin S, Stenzl A, Rammensee HG, Stevanovic S: Moderate degradation does not preclude microarray analysis of small amounts of RNA Biotechniques 2003, 35(6): I 192-I I96.

49. Vandesompele J, De Preter K, Pattyn F, Poppe B, Van Roy N, De Paepe A, Speleman F: Accurate normalization of real-time quantitative RT-PCR data by geometric averaging of multiple internal control genes. Genome Biol 2002 3(7):RESEARCH0034.

50. Bertrand N, Castro DS, Guillemot F: Proneural genes and the specification of neural cell types. Nat Rev Neurosci 2002 3(7):517-530

51. Gammill LS, Bronner-Fraser M: Neural crest specification: migrating into genomics. Nat Rev Neurosci 2003, 4( I 0):795-805.

52. Guillemot F: Vertebrate bHLH genes and the determination of neuronal fates. Exp Cell Res 1999, 253(2):357-364.

53. Knecht $A K$, Bronner-Fraser M: Induction of the neural crest: a multigene process. Nat Rev Genet 2002, 3(6):453-46I.

54. Le Douarin NM, Dupin E: Multipotentiality of the neural crest. Curr Opin Genet Dev 2003, I3(5):529-536. 